\title{
Impact of successful restoration of sinus rhythm in patients with atrial fibrillation and acute heart failure: Results from the Korean Acute Heart Failure registry
}

\author{
Youngjin Cho ${ }^{1}$, Il-Young $\mathrm{Oh}^{1}$, Jin Joo Park ${ }^{1}$, Byung-Hee $\mathrm{Oh}^{2}$, Eun-Seok Jeon ${ }^{3}$, \\ Jae-Joong Kim ${ }^{4}$, Kyung-Kuk Hwang ${ }^{5}$, Myeong-Chan $\mathrm{Cho}^{5}$, Shung Chull Chae ${ }^{6}$,
} Sang Hong Baek ${ }^{7}$, Seok-Min Kang ${ }^{8}$, Byung-Su Yoo ${ }^{9}$, Youngkeun Ahn ${ }^{10}$, Dong-Ju Choi ${ }^{1}$

${ }^{1}$ Department of Internal Medicine, Seoul National University Bundang Hospital, Korea

${ }^{2}$ Department of Internal Medicine, Seoul National University Hospital, Seoul, Korea

${ }^{3}$ Department of Internal Medicine, Sungkyunkwan University College of Medicine, Seoul, Korea

${ }^{4}$ Department of Internal Medicine, University of Ulsan College of Medicine, Seoul, Korea ${ }^{5}$ Department of Internal Medicine, Chungbuk National University College of Medicine, Cheongju, Korea ${ }^{6}$ Department of Internal Medicine, Kyungpook National University College of Medicine, Daegu, Korea

${ }^{7}$ Department of Internal Medicine, The Catholic University of Korea, Seoul, Korea

${ }^{8}$ Department of Internal Medicine, Yonsei University College of Medicine, Seoul, Korea

${ }^{9}$ Department of Internal Medicine, Yonsei University Wonju College of Medicine, Wonju, Korea

${ }^{10}$ Department of Internal Medicine, Heart Research Center of Chonnam National University, Gwangju, Korea

\begin{abstract}
Background: Restoring and maintaining sinus rhythm (SR) in patients with atrial fibrillation $(A F)$ failed to show superior outcomes over rate control strategies in prior randomized trials. However, there is sparse data on their outcomes in patients with acute heart failure (AHF).

Methods: From December 2010 to February 2014, 5,625 patients with AHF from 10 tertiary hospitals were enrolled in the Korean Acute Heart Failure registry, including 1,961 patients whose initial electrocardiogram showed AF. Clinical outcomes of patients who restored SR by pharmacological or electrical cardioversion (SR conversion group, $n=212$ ) were compared to those of patients who showed a persistent $A F$ rhythm ( $A F$ persistent group, $n=1,662$ ).

Results: All-cause mortality both in-hospital and during the follow-up (median 2.5 years) were significantly lower in the SR conversion group than in the AF persistent group after adjustment for risk factors (adjusted hazard ratio [HR]; 95\% confidence interval [CI] $=0.26[0.08-0.88], p=0.031$ and 0.59 [0.43-0.82], $p=0.002$, for mortality in-hospital and during follow-up, respectively). After 1:3 propensity score matching (SR conversion group $=167, A F$ persistent group $=501)$, successful restoration of SR was associated with lower all-cause mortality $(\mathrm{HR}[95 \% \mathrm{CI}]=0.68$ [0.49-0.93], $p=0.015)$, heart failure rehospitalization (HR [95\% CI] $=0.66[0.45-0.97], p=0.032)$, and composite of death and heart failure rehospitalization (HR [95\% CI] $=0.66[0.51-0.86], p=0.002)$.

Conclusions: Patients with $A H F$ and $A F$ had significantly lower mortality in-hospital and during follow-up if rhythm treatment for $A F$ was successful, underscoring the importance of restoring $S R$ in patients with AHF. (Cardiol J 2022; 29, 3: 472-480)
\end{abstract}

Key words: atrial fibrillation, acute heart failure, cardioversion

Address for correspondence: Dong-Ju Choi, MD, PhD, Professor, Department of Internal Medicine, Division of Cardiology, Cardiovascular Center, Seoul National University Bundang Hospital, 300 Gumi-dong, Bundang-gu, Seongnam city, Gyeonggi-do, 13620, South Korea, tel: 82-31-787-7007, e-mail: djchoi@snubh.org

Received: 12.05.2020 Accepted: 23.07.2020 Early publication date: 11.08.2020

This article is available in open access under Creative Common Attribution-Non-Commercial-No Derivatives 4.0 International (CC BY-NC-ND 4.0) license, allowing to download articles and share them with others as long as they credit the authors and the publisher, but without permission to change them in any way or use them commercially. 


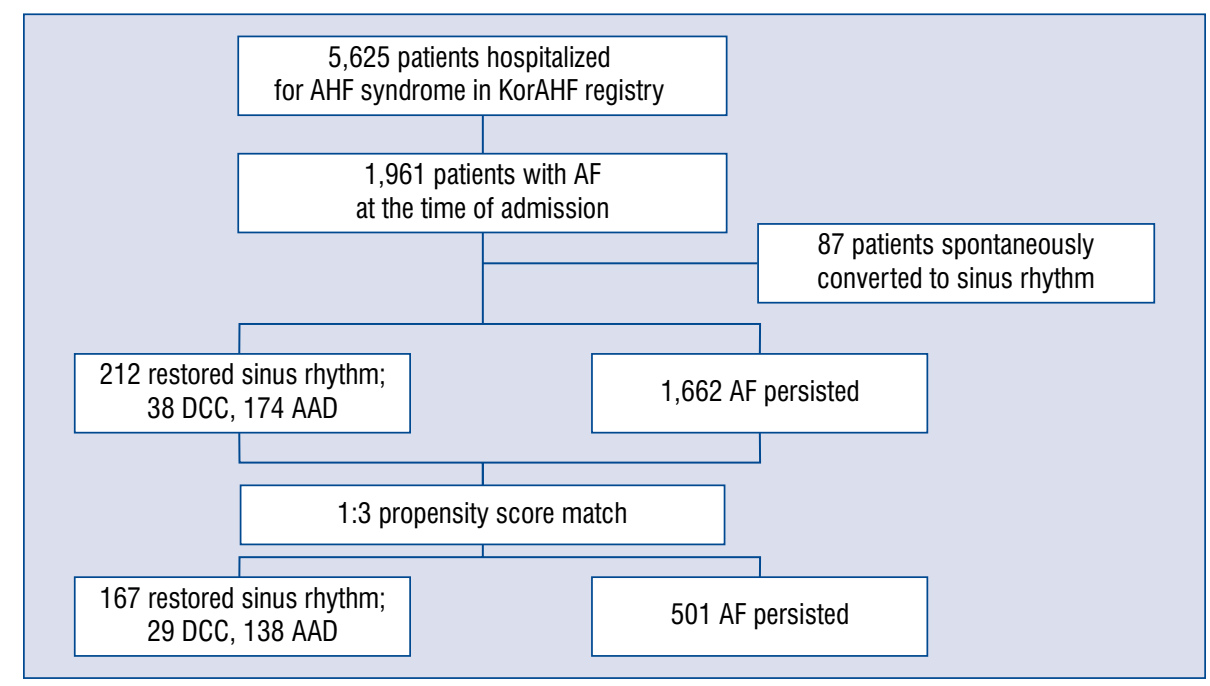

Figure 1. Flowchart of the study population; $A A D$ - anti-arrhythmic drug; $A F$ - atrial fibrillation; AHF — acute heart failure; DCC — direct current cardioversion; KorAHF — The Korean Acute Heart Failure registry.

\section{Introduction}

Atrial fibrillation (AF) and heart failure (HF) are very prevalent cardiovascular diseases resulting in enormous healthcare expenditures and patient suffering. They share risk factors, often coexist, and affect each other's outcomes [1-3]. Therefore, the importance for the proper management of $\mathrm{AF}$ in patients with $\mathrm{HF}$ is growing. Rhythm control strategies for $\mathrm{AF}$ management - restoring and maintaining sinus rhythm (SR) - failed to show superior outcomes in terms of mortality in prior randomized trials. In the AFFIRM trial, around 4,000 patients with AF and risk factors for stroke or death were randomized and treated either with rhythm control or rate control strategies, and it was suggested that rate control strategies might be potentially advantageous because of their lower risk of adverse drug effects. However, it was also suggested that rhythm control strategies might be beneficial in higher risk patients with $\mathrm{AF}$ [4]. In the AF-CHF trial, patients with both $\mathrm{AF}$ and chronic HF were enrolled, and it also failed to show a superior impact of rhythm control strategies over rate control strategies [5]. However, there are limited data on the impact of conversion to SR from $\mathrm{AF}$ in patients with acute heart failure (AHF). The aim of this study was to investigate the outcomes after rhythm treatment in patients with $\mathrm{AHF}$ and $\mathrm{AF}$.

\section{Methods}

Study population and Korean Acute Heart Failure registry

The Korean Acute Heart Failure (KorAHF) registry is a prospective multicenter cohort study that is currently ongoing. Patients are consecutively enrolled upon initial hospital admission for AHF syndrome and are followed up accordingly. The registry is accumulating data on individual patients, not individual hospitalizations. Information on the objectives of the study design and study population is provided in the clinical trial registration (ClinicalTrial.gov NCT01389843), and the design and the purpose of the KorAHF registry have been published elsewhere [6, 7]. Among a total of 5,625 patients with AHF enrolled in this registry, the initial electrocardiograms of 1,933 patients showed AF. Excluding 87 patients who spontaneously converted to SR without any rhythm treatment, herein, 212 patients were compared who had restoration of SR and its maintenance until discharge (SR conversion group) with 1,662 patients who showed a persistent AF rhythm (AF persistent group). The study population flow diagram is presented in Figure 1 . The study protocol was approved by the ethics committee or institutional review board at each hospital (IRB No. B-1104-125-014). The need for written informed consent was waived by the institutional review board. The study complied with the Declaration of Helsinki.

\section{Rhythm treatment for atrial fibrillation}

Restoration of SR as well as the modality of rhythm treatment in patients with AHF and $\mathrm{AF}$ were left to the individual physician's choice. Both electrical $(n=38)$ and pharmacological cardioversion $(\mathrm{n}=174)$ were included as adequate rhythm treatment. When AF spontaneously converted to $S R$, the patient was excluded from the analysis. 


\section{Clinical follow-up and endpoints}

The attending physician completed a webbased case report form in the Clinical Data Management System (iCReaT) from the Korea National Institute of Health (NIH) with the assistance of a clinical research coordinator. The latest information on patient clinical manifestation, biochemistry, and medication was collected at the first follow-up visit at 30 days and again at follow-up visits at 3,6 , $12,24,36,48$, and 60 months. The follow-up data were collected from the patients by the attending physician and stored in the web-based case report form. The outcome data on subjects who were not followed-up were ascertained by telephone interview. In addition, the outcome data on patients lost to follow-up were collected from the National Death Records. The primary endpoint of this study was the all-cause mortality rate. The in-hospital outcomes, especially in-hospital mortality were also evaluated. All deaths were considered cardiac unless a definite non-cardiac cause could be established. All outcome data reported from the participating centers were reviewed by an independent clinical event adjudicating committee.

\section{Statistical analysis}

The Student t-test and $\chi^{2}$ or the Fisher exact test were used to compare means and proportions of baseline clinical characteristics between the two groups. To address potential sources of bias and confounding factors in this retrospective study, propensity analysis was performed. Baseline clinical characteristics were incorporated into a non-parsimonious logistic regression model to compute the propensity score for $\mathrm{AF}$ rhythm treatment. The included covariates were age, sex, diabetes, hypertension, ischemic heart disease, cerebrovascular disease, chronic kidney disease, malignancy, serum hemoglobin and creatinine levels, high B-type natriuretic peptide (BNP, $>500 \mathrm{pg} /$ $/ \mathrm{mL}$ ) or N-terminal pro-BNP (NT-proBNP, $>1000$ $\mathrm{pg} / \mathrm{mL}$ ), left ventricular ejection fraction (LVEF), type of HF (de novo vs. acute decompensated), tachycardia as an etiology of AHF, new-onset AF, admission to the intensive care unit (ICU), and mechanical ventilation support $(\mathrm{C}$-statistics $=0.739)$. 1:3 propensity score-matching iteration were then performed from the fifth digit to the first digit and 167 patients with restoration of SR were matched to 501 patients with persistent AF. Baseline characteristics of the two groups were compared again in this matched population. The Cox proportional hazard model was used to estimate the hazard ratio (HR) and $95 \%$ confidence interval $(95 \% \mathrm{CI})$ for the clinical outcomes of the two groups. All of the statistical analyses were performed using $R$ version 3.6.0, and $p<0.05$ was considered statistically significant.

\section{Results}

\section{Baseline characteristics}

Baseline clinical characteristics of the overall study population and propensity score-matched population are shown in Table 1. An SR was more frequently restored in relatively younger patients with lower $\mathrm{CHA}_{2} \mathrm{DS}_{2}$-VASc scores. Hypertension and chronic kidney disease tended to be more prevalent in the AF persistent group. The proportion of new-onset $\mathrm{AF}$, de novo $\mathrm{HF}$, and elevated $\mathrm{BNP}$ (or NT-proBNP) was higher in the SR conversion group. The SR conversion group included more patients who were admitted to ICU or had mechanical ventilator support. The LVEF was significantly lower and the left atrium dimension was smaller in the SR conversion group. These parameters were all comparable between the groups after propensity score matching.

\section{In-hospital outcomes}

The median duration of hospitalization was 8 days (interquartile range [IQR], 5-13), and overall in-hospital mortality was $4.2 \%$ in patients with AHF presenting with AF. The median duration of hospitalization was 11 days (IQR, 7-19) in the SR conversion group and 7 days (IQR, 5-13) when AF persisted. Comparisons of in-hospital outcomes between the SR conversion and AF persistent groups are presented in Table 2. In-hospital allcause mortality was $4.2 \%$ in both groups (unadjusted odds ratio [OR], 95\% confidence interval $[95 \% \mathrm{CI}]=1.01[0.44-2.07], \mathrm{p}=0.982$ ), but after adjustment for age, sex, comorbidities, type of HF, new-onset AF, laboratory tests, echocardiographic parameters, ICU admission, and mechanical ventilation, all-cause mortality was significantly lower in the SR conversion group than in the AF persistent group (adjusted OR [95\% CI] $=0.26$ [0.08-0.88], $\mathrm{p}=0.031)$. Cardiovascular mortality and cerebral vascular events were not different between the two groups, regardless of the adjustments. After propensity score matching, the overall mortality was $2.4 \%$ in SR restored patients and $5.9 \%$ in $\mathrm{AF}$ persisted patients (OR [95\% CI] $=0.39$ [0.10-1.00], $\mathrm{p}=0.050)$. Cardiovascular mortality and the incidence of cerebral vascular accident were not significantly different between the SR conversion and $\mathrm{AF}$ persistent groups. 
Table 1. Baseline characteristics.

\begin{tabular}{|c|c|c|c|c|c|c|}
\hline & \multicolumn{3}{|c|}{ Overall AF patients } & \multicolumn{3}{|c|}{ Matched population } \\
\hline & $\begin{array}{l}\text { SR restored } \\
(n=212)\end{array}$ & $\begin{array}{c}\text { AF } \\
(n=1,662)\end{array}$ & $\mathbf{P}$ & $\begin{array}{l}\text { SR restored } \\
\qquad(n=167)\end{array}$ & $\begin{array}{c}\text { AF } \\
(n=501)\end{array}$ & $\mathbf{P}$ \\
\hline Age [years] & $67 \pm 14$ & $71 \pm 12$ & $<0.001$ & $68 \pm 13$ & $68 \pm 14$ & 0.840 \\
\hline Male & $104(49.1)$ & $866(52.1)$ & 0.403 & $83(49.7)$ & $274(54.7)$ & 0.303 \\
\hline Hypertension & $114(53.8)$ & $999(60.1)$ & 0.077 & $91(57.7)$ & $226(54.5)$ & 0.528 \\
\hline Diabetes mellitus & $57(26.9)$ & $483(29.1)$ & 0.510 & $46(27.5)$ & $147(29.3)$ & 0.730 \\
\hline CAD & 37 (17.5) & $346(20.8)$ & 0.262 & $32(19.2)$ & $116(23.2)$ & 0.333 \\
\hline Valvular heart disease & $41(19.3)$ & $393(23.6)$ & 0.162 & $32(19.2)$ & $77(15.4)$ & 0.304 \\
\hline Cerebrovascular disease & $32(15.1)$ & $325(19.6)$ & 0.119 & $22(13.2)$ & $62(12.4)$ & 0.893 \\
\hline CKD & $17(8.0)$ & $197(11.9)$ & 0.098 & $14(8.4)$ & $43(8.6)$ & 1.00 \\
\hline De novo heart failure & $115(54.2)$ & $705(42.4)$ & 0.001 & $90(53.9)$ & $271(54.1)$ & 1.00 \\
\hline Lung congestion & $164(77.4)$ & $1303(78.4)$ & 0.729 & $112(76.6)$ & $410(81.8)$ & 0.176 \\
\hline Previous HF admission & $65(30.7)$ & $652(39.3)$ & 0.019 & $52(31.1)$ & $147(29.3)$ & 0.732 \\
\hline New onset $A F$ & $108(51.9)$ & $499(30.4)$ & $<0.001$ & $85(50.9)$ & $261(52.1)$ & 0.858 \\
\hline Tachycardia induced HF & $105(49.5)$ & $729(43.9)$ & 0.118 & $88(52.7)$ & $251(50.1)$ & 0.623 \\
\hline $\mathrm{CHA}_{2} \mathrm{DS}_{2}$-VASc score & $4.4 \pm 1.7$ & $4.8 \pm 1.7$ & 0.001 & $4.4 \pm 1.7$ & $4.4 \pm 1.5$ & 0.766 \\
\hline Malignancy & $21(9.9)$ & $132(7.9)$ & 0.326 & $16(9.6)$ & $39(7.8)$ & 0.569 \\
\hline ICU admission & $134(63.2)$ & $642(38.6)$ & $<0.001$ & 99 (59.3) & $297(59.3)$ & 1.00 \\
\hline Mechanical ventilation & $54(25.5)$ & $172(10.3)$ & $<0.001$ & $33(19.8)$ & $98(19.6)$ & 1.00 \\
\hline Hemoglobin $[\mathrm{g} / \mathrm{dL}]$ & $12.7 \pm 2.2$ & $12.7 \pm 2.2$ & 0.903 & $12.8 \pm 2.2$ & $12.8 \pm 2.1$ & 0.693 \\
\hline Creatinine $[\mathrm{mg} / \mathrm{dL}]$ & $1.3 \pm 1.4$ & $1.3 \pm 1.0$ & 0.939 & $1.2 \pm 0.9$ & $1.3 \pm 0.8$ & 0.604 \\
\hline High BNP or NT-proBNP & $162(88.0)$ & $1220(81.4)$ & 0.034 & $128(88.9)$ & $424(91.0)$ & 0.557 \\
\hline LVEF [\%] & $37 \pm 16$ & $41 \pm 16$ & $<0.001$ & $37 \pm 17$ & $36 \pm 16$ & 0.550 \\
\hline LA dimension [mm] & $49 \pm 10$ & $54 \pm 10$ & $<0.001$ & $50 \pm 10$ & $50 \pm 8$ & 0.882 \\
\hline \multicolumn{7}{|l|}{ Discharge medication: } \\
\hline ACEI or ARB & $123(58.0)$ & 1062 (63.9) & 0.110 & $102(61.1)$ & $323(64.5)$ & 0.486 \\
\hline Beta-blocker & $99(46.7)$ & $802(48.3)$ & 0.723 & $78(46.7)$ & $270(53.9)$ & 0.128 \\
\hline
\end{tabular}

Data are expressed as number (\%) or mean \pm standard deviation. ACEI — angiotensin-converting enzyme inhibitor; AF — atrial fibrillation; ARB - angiotensin receptor blocker; BNP - B-type natriuretic peptide; CAD - coronary artery disease; CKD - chronic kidney disease; HF - heart failure; ICU — intensive care unit; LA — left atrium; LVEF — left ventricular ejection fraction; NT-proBNP — N-terminal-pro B-type natriuretic peptide; SR - sinus rhythm

\section{Mortality and HF rehospitalization during follow-up}

The overall mortality rates at 1,2 , and 3 -year follow-up were $18.9 \%, 23.6 \%$, and $27.2 \%$ when SR was successfully restored, and $22.9 \%, 31.3 \%$, and $38.2 \%$ when $\mathrm{AF}$ persisted, respectively. The median follow-up duration was 2.5 years. Univariate survival analysis indicated that old age and various co-morbidities significantly increased the risk of death after AHF. Type of AHF (de novo vs. acute decompensated HF), timing of AF onset (newly diagnosed vs. previously diagnosed), laboratory tests, and discharge medications were also significantly correlated with mortality (Table 3 ). The SR conversion group showed significantly lower mortality than the AF persistent group in both the unadjusted (unadjusted HR [95\% CI] = $=0.70$ [0.54-0.91], $\mathrm{p}=0.007)$ and adjusted analysis (adjusted HR [95\% CI] $=0.59$ [0.43-0.82], $\mathrm{p}=0.002)$. HF rehospitalization rate tended to be lower in the SR conversion group (unadjusted HR $[95 \% \mathrm{CI}]=0.60$ [0.47-0.77], $\mathrm{p}=0.001$; adjusted HR [95\% CI] $=0.72$ [0.49-1.05], $\mathrm{p}=0.084)$. The composite of death and $\mathrm{HF}$ rehospitalization rate was lower in the SR conversion group than in the AF persistent group (unadjusted HR [95\% $\mathrm{CI}]=0.60$ [0.47-0.77], $\mathrm{p}=0.001$; adjusted HR $[95 \% \mathrm{CI}]=0.65[0.49-0.85], \mathrm{p}=0.002)$. Kaplan-Meier curves for cumulative incidences of outcome events are presented in Figure 2.

After propensity score matching, all-cause mortality was still significantly lower in the SR 


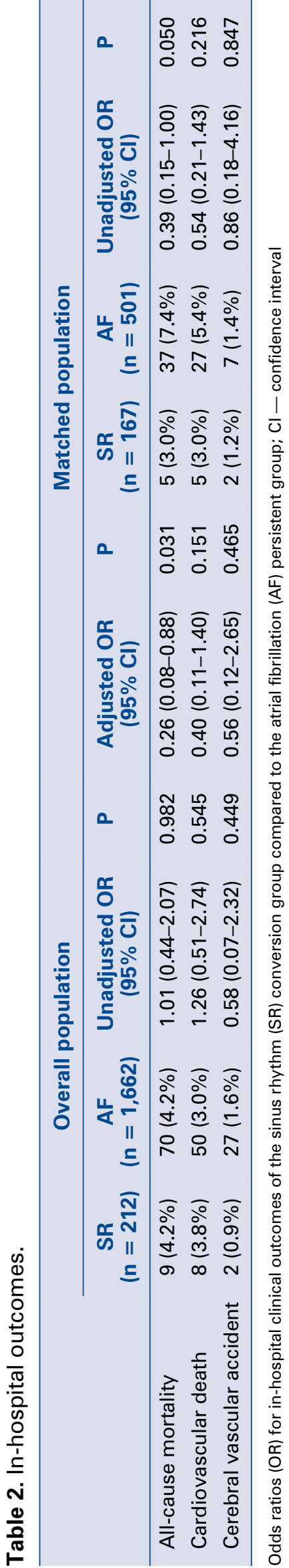

Table 3. Predictors for all-cause mortality at follow-up in an overall population.

\begin{tabular}{|c|c|c|}
\hline & $\begin{array}{c}\text { Unadjusted HR } \\
(95 \% \mathrm{CI})\end{array}$ & $\mathbf{P}$ \\
\hline Conversion to SR & $0.70(0.54-0.91)$ & 0.007 \\
\hline Age (per 1 year) & 1.05 (1.04-1.05) & $<0.001$ \\
\hline Male & $1.05(0.91-1.22)$ & 0.481 \\
\hline Hypertension & $1.36(1.17-1.59)$ & $<0.001$ \\
\hline Diabetes & $1.52(1.31-1.77)$ & $<0.001$ \\
\hline $\begin{array}{l}\text { Ischemic heart } \\
\text { disease }\end{array}$ & $1.51(1.28-1.79)$ & $<0.001$ \\
\hline $\begin{array}{l}\text { Valvular heart } \\
\text { disease }\end{array}$ & $1.34(1.14-1.58)$ & $<0.001$ \\
\hline $\begin{array}{l}\text { Cerebrovascular } \\
\text { disease }\end{array}$ & $1.48(1.25-1.76)$ & $<0.001$ \\
\hline CKD & $2.36(1.96-2.85)$ & $<0.001$ \\
\hline ADHF (vs. de novo) & $1.77(1.51-2.06)$ & $<0.001$ \\
\hline Lung congestion & $1.27(1.06-1.54)$ & 0.011 \\
\hline $\begin{array}{l}\text { Previous HF } \\
\text { admission }\end{array}$ & $1.80(1.55-2.10)$ & $<0.001$ \\
\hline New onset AF & $0.80(0.68-0.94)$ & 0.007 \\
\hline $\begin{array}{l}\text { Tachycardia- } \\
\text {-induced HF }\end{array}$ & $0.61(0.52-0.71)$ & $<0.001$ \\
\hline Malignancy & $1.36(1.07-1.73)$ & 0.013 \\
\hline ICU admission & $1.27(1.10-1.48)$ & 0.001 \\
\hline $\begin{array}{l}\text { Mechanical } \\
\text { ventilation }\end{array}$ & $1.75(1.43-2.14)$ & $<0.001$ \\
\hline $\begin{array}{l}\text { Hemoglobin } \\
\text { (per } 1 \mathrm{~g} / \mathrm{dL} \text { ) }\end{array}$ & $0.81(0.79-0.84)$ & $<0.001$ \\
\hline $\begin{array}{l}\text { Creatinine } \\
\text { (per } 1 \mathrm{mg} / \mathrm{dL} \text { ) }\end{array}$ & $1.17(1.13-1.21)$ & $<0.001$ \\
\hline $\begin{array}{l}\text { High BNP } \\
\text { or NT-proBNP }\end{array}$ & $1.36(1.09-1.68)$ & 0.006 \\
\hline LVEF > $40 \%$ & $1.03(0.88-1.20)$ & 0.745 \\
\hline LA (per $1 \mathrm{~mm}$ ) & $1.01(1.00-1.01)$ & 0.134 \\
\hline $\begin{array}{l}\text { ACEI or ARB } \\
\text { at discharge }\end{array}$ & $0.57(0.49-0.65)$ & $<0.001$ \\
\hline $\begin{array}{l}\text { Beta-blocker } \\
\text { at discharge }\end{array}$ & $0.59(0.51-0.68)$ & $<0.001$ \\
\hline
\end{tabular}

ADHF — acute decompensated heart failure; $\mathrm{Cl}$ - confidence interval; HR - hazard ratio; other abbreviations as for Table 1

conversion group $(\mathrm{HR}$ [95\% CI] $=0.68$ [0.49-0.93], $\mathrm{p}=0.015)$. HF rehospitalization and the composite of mortality and HF rehospitalization were also lower in the SR group than in the AF persistent group (HF rehospitalization: $\mathrm{HR}[95 \% \mathrm{CI}]=0.66$ [0.45-0.97], $\mathrm{p}=0.032$, composite of mortality/HF rehospitalization: $\mathrm{HR}[95 \% \mathrm{CI}]=0.66$ [0.51-0.86], $\mathrm{p}=0.002$ ) (Fig. 3).

In subgroup analysis, successful SR conversion was significantly associated with lower mortal- 


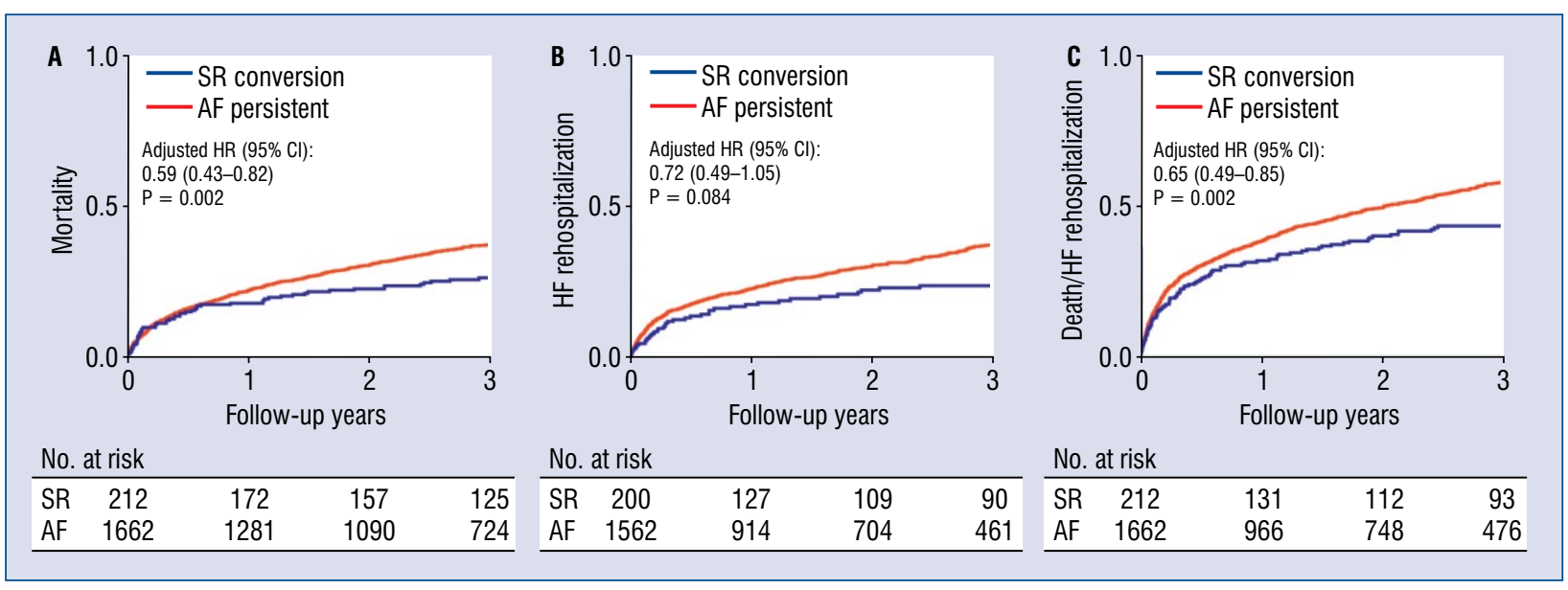

Figure 2. Clinical outcomes in overall study population; A. Mortality; B. Heart failure (HF) rehospitalization; C. Composite of mortality and HF rehospitalization; $\mathrm{AF}$ - atrial fibrillation; $\mathrm{Cl}$ - confidence interval; $\mathrm{HR}$ - hazard ratio; SR - sinus rhythm.

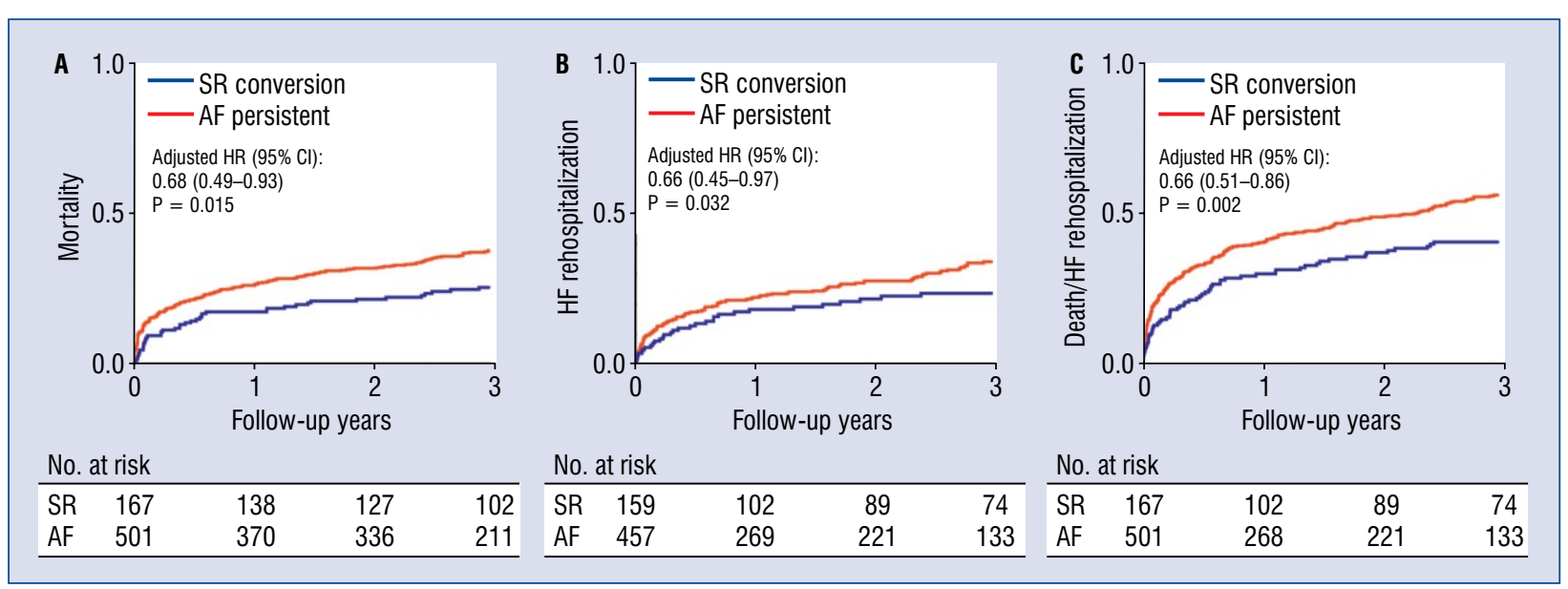

Figure 3. Clinical outcomes in a propensity-score matched population; A Mortality; B. Heart failure (HF) rehospitalization; C. Composite of mortality and HF rehospitalization; abbreviations as for Figure 2.

ity rate in patients with hypertension, in contrast to patients without hypertension, where there was no difference in mortality between the SR conversion and $\mathrm{AF}$ persistent group (interaction $\mathrm{p}=0.021$ ). Other than hypertension, the beneficial effect of successful SR conversion for patients with AHF and AF did not, in terms of mortality, significantly differ according to age, sex, diabetes mellitus, onset of AF, and the type or aetiology of HF (Table 4).

\section{Cerebrovascular events during follow-up}

Cerebrovascular accident rates at the 3-year follow-up were $3.1 \%$ when SR was restored and $2.3 \%$ when $\mathrm{AF}$ persisted (HR $[95 \% \mathrm{CI}]=1.28$ [0.50-3.28], $\mathrm{p}=0.614)$ in the crude study popula- tion. After propensity score matching, cerebrovascular event rates were $3.3 \%$ and $3.1 \%$ (HR [95\% $\mathrm{CI}]=1.28$ [0.44-3.67], $\mathrm{p}=0.652)$, respectively.

\section{Discussion}

The benefit of rhythm control over rate control strategies in patients with $\mathrm{AF}$ has been controversial thus far in terms of mortality $[4,5,8,9]$. Therefore, the current guidelines recommend restoration and maintenance of SR mainly in patients with symptomatic AF [10]. However, very high-risk patients with $\mathrm{AF}$, such as the patients with AHF in the present study, have not been adequately evaluated. The data showed a significantly 
Table 4. Subgroup analysis for mortality in a matched population.

\begin{tabular}{|c|c|c|c|c|}
\hline & No. of patients & Adjusted HR (95\% CI) & $\mathbf{P}$ & Interaction $\mathrm{P}$ \\
\hline \multicolumn{5}{|l|}{ Age: } \\
\hline$\geq 65$ years & 429 & $0.43(0.28-0.64)$ & $<0.001$ & 0.283 \\
\hline$<65$ years & 239 & $0.78(0.35-1.73)$ & 0.549 & \\
\hline \multicolumn{5}{|l|}{ Gender: } \\
\hline Male & 357 & $0.38(0.23-0.65)$ & $<0.001$ & 0.139 \\
\hline Female & 311 & $0.63(0.39-1.04)$ & 0.068 & \\
\hline \multicolumn{5}{|c|}{ Diabetes mellitus: } \\
\hline Yes & 193 & $0.64(0.33-1.24)$ & 0.184 & 0.511 \\
\hline No & 475 & $0.48(0.31-0.74)$ & 0.001 & \\
\hline \multicolumn{5}{|l|}{ Hypertension: } \\
\hline Yes & 380 & $0.34(0.21-0.54)$ & $<0.001$ & 0.021 \\
\hline No & 288 & $0.89(0.51-1.57)$ & 0.703 & \\
\hline \multicolumn{5}{|l|}{ New-onset AF: } \\
\hline Yes & 346 & $0.34(0.19-0.60)$ & $<0.001$ & 0.216 \\
\hline No & 322 & $0.56(0.34-0.91)$ & 0.019 & \\
\hline \multicolumn{5}{|l|}{ Type of HF: } \\
\hline De novo & 361 & $0.35(0.19-0.65)$ & $<0.001$ & 0.101 \\
\hline $\mathrm{ADHF}$ & 307 & $0.62(0.39-0.99)$ & 0.043 & \\
\hline \multicolumn{5}{|l|}{ Etiology of HF: } \\
\hline Ischemic & 148 & $0.40(0.18-0.86)$ & 0.019 & 0.229 \\
\hline Non-ischemic & 520 & $0.55(0.36-0.83)$ & 0.005 & \\
\hline
\end{tabular}

Abbreviations as for Tables 1 and 3 .

lower in-hospital mortality rate when initial AF was successfully converted to SR either by drugs or electrical cardioversion in patients with AHF after adjustments for various covariates. And interestingly, this beneficial effect on mortality persisted during the long-term follow-up. The HF readmission rate was also lower in the SR conversion group in the matched population. There was no significant difference in terms of cerebrovascular events, both in-hospital and during follow-up.

Atrial fibrillation and $\mathrm{HF}$ are two very prevalent cardiovascular diseases, often considered to be epidemic $[1,11]$. These two cardiovascular diseases share many risk factors, such as ageing, hypertension, diabetes mellitus, and underlying ischemic/valvular heart disease. Moreover, $\mathrm{AF}$ and HF can aggravate each other. There are several suggested mechanisms by which AF facilitates the development of HF. First, AF decreases cardiac output not only because of the consequences of poor ventricular rate control but also those of irregular ventricular filling and loss of atrial contraction. Decreased cardiac output augments neuro-hormonal activation observed in HF. Func- tional mitral annular enlargement is another possible explanation for HF development in patients with AF. On the other hand, HF can also cause AF development through atrial enlargement, vasoconstrictive neuro-hormonal milieu, and atrial fibrosis $[1,12]$. These interconnections between $\mathrm{AF}$ and HF lead to a high prevalence of AF in patients with HF [13], which was $27 \%$ in this KorAHF registry. Beyond its high prevalence, there is evidence that $\mathrm{AF}$ involves increased adverse events in patients with congestive HF. In participants of the Framingham Heart Study, AF and HF showed a temporal association, and concomitant $\mathrm{AF}$ and $\mathrm{HF}$ resulted in a lower survival rate [14]. Retrospective post-hoc analysis of the SOLVD (Studies of Left Ventricular Dysfunction) Prevention and Treatment trials demonstrated that the presence of $\mathrm{AF}$ increased the risk of all-cause mortality in patients with left ventricular systolic dysfunction [15]. A recent meta-analysis of randomized trials concluded that $\mathrm{AF}$ increased adverse events in patients with chronic $\mathrm{HF}$ after adjusting for other clinical risk factors (adjusted OR 1.40) [16]. Regarding the timing of $\mathrm{AF}$ and $\mathrm{HF}$ diagnosis, a community-based study 
suggested that the negative effect of AF on patients with $\mathrm{HF}$ was greater with incident $\mathrm{AF}$ than with prevalent AF [17]. The Framingham cohort [14] and MADIT II (Multicenter Automatic Defibrillator Trial II) trial demonstrated supporting results [18].

On the other hand, the impact of concomitant $\mathrm{AF}$ in patients presenting with AHF syndrome appears less clear. In contrast to the results from patients with chronic HF, data from the ATTEND registry showed no difference in 30-day all-cause mortality between patients with $(3.04 \%)$ or without AF (3.88\%) [13]. Additionally, in the KorAHF registry, the in-hospital all-cause mortality of the AF population $(4.2 \%)$ was not different from that of the overall population (5.3\%). These results might suggest that $\mathrm{AF}$ is not a worse etiology or more aggravating factor for AHF syndrome than other etiologic factors, although $\mathrm{AF}$ is a significant risk factor for adverse outcomes in patients with chronic HF.

Despite the increase in adverse events by the presence of $\mathrm{AF}$ in patients with congestive $\mathrm{HF}$, large randomized trials such as the AF-CHF (Atrial Fibrillation and Congestive Heart Failure) study [5] and DIAMOND-CHF trial (Danish Investigations of Arrhythmia and Mortality on Dofetilide in Congestive Heart Failure) [19] demonstrated no benefit of a rhythm control strategy in those patients. However, this result was often accounted for by the adverse effects of anti-arrhythmic drugs, especially in AF patients with left ventricular dysfunction, and the benefit of maintaining SR itself was not completely denied. Maintaining SR using catheter ablation has been reported to improve functional capacity and LVEF compared with the rate control strategy [20-22], and more recent trials demonstrated a survival benefit of catheter ablation in patients with $\mathrm{AF}$ and chronic $\mathrm{HF}$, emphasising the importance of maintaining SR itself [23-25]. Data herein, also suggest the importance of attempts to maintain SR in AF patients with an acute setting of HF.

In the setting of AHF with $\mathrm{AF}$, benefits of the restoration of SR have not been adequately evaluated, perhaps because of difficulties in conducting large randomized clinical trials in this population. In the KorAHF registry, all-cause mortality was significantly lower when initial AF was converted to SR either by drug (amiodarone) or electrical cardioversion in patients with AHF. Despite emerging evidence for the benefit of catheter ablation in patients with $\mathrm{AF}$ and congestive $\mathrm{HF}$, performing catheter ablation is not widely accepted in the setting of AHF syndrome. Therefore, the present study data may reflect the clinical outcomes of rhythm control strategies in a daily practice setting. In this study, there was no difference in in-hospital mortality irrespective of whether AF persisted or successful conversion to SR was acquired in the overall population. However, after adjustments for various clinical predictors for mortality, in-hospital mortality was significantly better in the SR conversion group. Interestingly, the beneficial effect of conversion to SR in patients with $\mathrm{AHF}$ and $\mathrm{AF}$ was still significant after discharge from the index $\mathrm{HF}$ admission, suggesting the importance of adequate treatment of the index HF admission. Restoring $\mathrm{SR}$ and maintaining it during index HF admission appeared to affect not only the in-hospital outcomes but also the long-term outcomes over several years.

\section{Limitations of the study}

There were several limitations to this study. This was a non-randomized, registry-based study and might have been affected by unmeasured confounding factors. Since the attending physician's intension regarding AF treatment strategy (rhythm control vs. rate control) was not collected in this registry, the definition of the present study groups is different from that of the rhythm and rate control strategy groups in previous randomized trials. The KorAHF registry did not collect data on the rhythm status during follow-up, thus further analysis according to the recurrence of AF during follow-up was not available. Further studies are warranted to confirm the effect of rhythm control strategies for $\mathrm{AF}$ in these high-risk patients with AHF.

\section{Conclusions}

In this large multicenter KorAHF registry, patients with AHF and AF had significantly lower future mortality rates when rhythm treatments for $\mathrm{AF}$ were successfully applied. These results underscore the importance of restoring SR in patients presenting with AHF.

\section{Acknowledgments}

This work was supported by the Research of Korea Centers for Disease Control and Prevention [2010-E63003-00, 2011-E63002-00, 2012E63005-00, 2013-E63003-00, 2013-E63003-01, 2013-E63003-02, and 2016-ER6303-00] and by the SNUBH Research Fund [Grant no. 14-2015-029, 16-2017-003].

Conflict of interest: None declared 


\section{References}

1. Verma A, Kalman JM, Callans DJ. Treatment of patients with atrial fibrillation and heart failure with reduced ejection fraction. Circulation. 2017; 135(16): 1547-1563, doi: 10.1161/CIRCULATIONAHA.116.026054, indexed in Pubmed: 28416525.

2. January CT, Wann LS, Calkins H, et al. 2019 AHA/ACC/HRS Focused Update of the 2014 AHA/ACC/HRS Guideline for the Management of Patients With Atrial Fibrillation. J Am Coll Cardiol. 2019; 74(1): 104-32.

3. January CT, Wann LS, Alpert JS, et al. 2014 AHA/ACC/HRS guideline for the management of patients with atrial fibrillation: a report of the American College of Cardiology/American Heart Association Task Force on Practice Guidelines and the Heart Rhythm Society. J Am Coll Cardiol. 2014; 64(21): e1-76.

4. Wyse DG, Waldo AL, DiMarco JP, et al. A comparison of rate control and rhythm control in patients with atrial fibrillation. $\mathrm{N}$ Engl J Med. 2002; 347(23): 1825-1833, doi: 10.1056/NEJMoa021328, indexed in Pubmed: 12466506.

5. Roy D, Talajic M, Nattel S, et al. Rhythm control versus rate control for atrial fibrillation and heart failure. N Engl J Med. 2008; 358(25): 2667-2677, doi: 10.1056/NEJMoa0708789, indexed in Pubmed: 18565859.

6. Lee SE, Cho HJ, Lee HY, et al. A multicentre cohort study of acute heart failure syndromes in Korea: rationale, design, and interim observations of the Korean Acute Heart Failure (KorAHF) registry. Eur J Heart Fail. 2014; 16(6): 700-708, doi: 10.1002/ ejhf.91, indexed in Pubmed: 24797348.

7. Lim NK, Lee SE, Lee HY, et al. Clinical Characteristics and Outcome of Acute Heart Failure in Korea: Results from the Korean Acute Heart Failure Registry (KorAHF). Korean Circ J. 2017; 47(3): 341-353, doi: 10.4070/kcj.2016.0419, indexed in Pubmed: 28567084.

8. Van Gelder IC, Hagens VE, Bosker HA, et al. A comparison of rate control and rhythm control in patients with recurrent persistent atrial fibrillation. N Engl J Med. 2002; 347(23): 1834-1840, doi: 10.1056/NEJMoa021375, indexed in Pubmed: 12466507.

9. Flaker GC, Blackshear JL, McBride R, et al. Antiarrhythmic drug therapy and cardiac mortality in atrial fibrillation. The Stroke Prevention in Atrial Fibrillation Investigators. J Am Coll Cardiol. 1992; 20(3): 527-532, doi: 10.1016/0735-1097(92)90003-6, indexed in Pubmed: 1512329.

10. Wann LS, Curtis AB, January CT, et al. 2011 ACCF/AHA/HRS Focused Update on the Management of Patients With Atrial Fibrillation (Updating the 2006 Guideline). A Report of the American College of Cardiology Foundation/American Heart Association Task Force on Practice Guidelines. J Am Coll Cardiol. 2011; 57(2): 223-242.

11. Braunwald E. Cardiovascular Medicine at the Turn of the Millennium: Triumphs, Concerns, and Opportunities. N Engl J Med. 1997; 337(19): 1360-1369, doi: 10.1056/nejm199711063371906.

12. Anter E, Jessup M, Callans DJ. Atrial fibrillation and heart failure: treatment considerations for a dual epidemic. Circulation. 2009; 119(18): 2516-2525, doi: 10.1161/CIRCULATIONAHA.108.821306, indexed in Pubmed: 19433768.

13. Kajimoto K, Sato N, Takano T, et al. investigators of the Acute Decompensated Heart Failure Syndromes (ATTEND) registry. Relationship of renal insufficiency and clinical features or comorbidities with clinical outcome in patients hospitalised for acute heart failure syndromes. Eur Heart J Acute Cardiovasc Care. 2016; 6(8): 697-708, doi: 10.1177/2048872616658586, indexed in Pubmed: 27363422.

14. Santhanakrishnan R, Wang Na, Larson MG, et al. Atrial fibrillation begets heart failure and vice versa: temporal associations and differences in preserved versus reduced ejection fraction. Circulation. 2016; 133(5): 484-492, doi: 10.1161/CIRCULATIONAHA.115.018614, indexed in Pubmed: 26746177.

15. Dries D, Exner D, Gersh B, et al. Atrial fibrillation is associated with an increased risk for mortality and heart failure progression in patients with asymptomatic and symptomatic left ventricular systolic dysfunction: a retrospective analysis of the SOLVD trials. J Am Coll Cardiol. 1998; 32(3): 695-703, doi: 10.1016/s07351097(98)00297-6.

16. Mamas MA, Caldwell JC, Chacko S, et al. A meta-analysis of the prognostic significance of atrial fibrillation in chronic heart failure. Eur J Heart Fail. 2009; 11(7): 676-683, doi: 10.1093/eurjhf/ hfp085, indexed in Pubmed: 19553398.

17. Chamberlain AM, Redfield MM, Alonso A, et al. Atrial fibrillation and mortality in heart failure: a community study. Circ Heart Fail. 2011; 4(6): 740-746, doi: 10.1161/CIRCHEARTFAILURE.111.962688, indexed in Pubmed: 21920917.

18. Zareba W, Steinberg J, McNitt S, et al. Implantable cardioverterdefibrillator therapy and risk of congestive heart failure or death in MADIT II patients with atrial fibrillation. Heart Rhythm. 2006; 3(6): 631-637, doi: 10.1016/j.hrthm.2006.02.012.

19. Torp-Pedersen C, Møller M, Bloch-Thomsen P, et al. Dofetilide in patients with congestive heart failure and left ventricular dysfunction. N Engl J Med. 1999; 341(12): 857-865, doi: 10.1056/ nejm199909163411201.

20. Anselmino M, Matta M, Castagno D, et al. Catheter ablation of atrial fibrillation in chronic heart failure: state-of-the-art and future perspectives. Europace. 2016; 18(5): 638-647, doi: 10.1093/ europace/euv368, indexed in Pubmed: 26857188.

21. Hunter RJ, Berriman TJ, Diab I, et al. A randomized controlled trial of catheter ablation versus medical treatment of atrial fibrillation in heart failure (the CAMTAF trial). Circ Arrhythm Electrophysiol. 2014; 7(1): 31-38, doi: 10.1161/CIRCEP.113.000806, indexed in Pubmed: 24382410.

22. Jones DG, Haldar SK, Hussain W, et al. A randomized trial to assess catheter ablation versus rate control in the management of persistent atrial fibrillation in heart failure. J Am Coll Cardiol. 2013; 61(18): 1894-1903, doi: 10.1016/j.jacc.2013.01.069, indexed in Pubmed: 23500267.

23. Di Biase L, Mohanty P, Mohanty S, et al. Ablation Versus Amiodarone for Treatment of Persistent Atrial Fibrillation in Patients With Congestive Heart Failure and an Implanted Device: Results From the AATAC Multicenter Randomized Trial. Circulation. 2016; 133(17): 1637-1644, doi: 10.1161/CIRCULATIONAHA.115.019406, indexed in Pubmed: 27029350.

24. Ullah W, Ling LH, Prabhu S, et al. Catheter ablation of atrial fibrillation in patients with heart failure: impact of maintaining sinus rhythm on heart failure status and long-term rates of stroke and death. Europace. 2016; 18(5): 679-686, doi: 10.1093/ europace/euv440, indexed in Pubmed: 26843584.

25. Marrouche N, Brachmann J, Andresen D, et al. Catheter ablation for atrial fibrillation with heart failure. N Engl J Med. 2018; 378(5): 417-427, doi: 10.1056/nejmoa1707855. 